\title{
URODYNAMIC EVALUATION: PERIURETHRAL STRIATED EMG VERSUS PERIANAL STRIATED EMG
}

\author{
By Inder Perkash, M.D., M.S., F.R.C.S. \\ Spinal Cord Injury Service, VA Medical Center, Palo Alto, CA; and \\ Stanford University Medical Center, Stanford, CA, USA
}

\begin{abstract}
Fifty consecutive spinal injury patients who underwent simultaneous EMG of the peri-urethral and perianal striated muscles along with cystometrogram on a multiple channel recorder are analysed. Bladder filling, voiding and also influence of spasticity on the EMG activity of both perianal and periurethral striated muscles were compared. Periurethral striated EMG along with CMG has a better diagnostic value (95 per cent) as compared to perianal EMG-CMG which was diagnostic in 72 per cent patients.
\end{abstract}

Key words: Urodynamic studies; Neurogenic bladder; Electromyography.

SimUltaneous cystometrography (CMG) and anal sphincter electromyography (EMG) have been widely used for the evaluation of neuro-muscular disorders of the bladder during the past Io years. Franksson and Peterson (1955) first reported EMG studies of periurethral striated muscle. Ruskin and Davis (I975) suggested independent function of the anal and external urethral sphincter. Earlier, DennyBrown and Robertson (1933) pointed out that defecation alternates with micturition in the normal, but in spinal man both acts occur simultaneously. Several other studies (Floyd \& Walls, I953; Kawakami, I954; Taverner \& Smiddy, I969) have also shown that any increase in intra-abdominal pressure in normal persons produces bursts of motor activity in the pelvic diaphragm (levator ani) and in the anal sphincter muscles. Therefore, there is potential difficulty in the interpretation of the results of CMG-anal EMG studies in normal persons when there is a rise in intra-abdominal pressure during urodynamic studies.

The present study evaluates CMG with simultaneous EMG of anal and periurethral striated muscle in 50 spinal injury patients. Motor unit activity of both sphincters was analysed as to the amplitude and number of motor units and also its relationship to CMG, particularly for the diagnosis of detrusor-sphincter dyssynergia.

\section{Methods and Materials}

Fifty male spinal injury patients with a mean age of 35.9 years (range 20 to 59 years) were studied. There were 20 tetraplegics, 22 paraplegics (TII and higher lesion) and eight cauda equina patients (below Ti I level). CMG was done through a size Io multiple hole catheter using carbon dioxide. Simultaneous EMG of periurethral and perianal striated sphincter were made using two coaxial needles.

Needle placement for EMG. For periurethral striated EMG, a 2 in long coaxial needle was placed close to the apex of the prostate gland through the perineum (see Fig. I). The patient was placed in the lithotomy position, with legs supported on stirrups. The needle was inserted about $\mathrm{I} \frac{1}{2} \mathrm{~cm}$ anterior to the anal margin and was directed to the apex of the prostate. This was guided with the index finger of the 

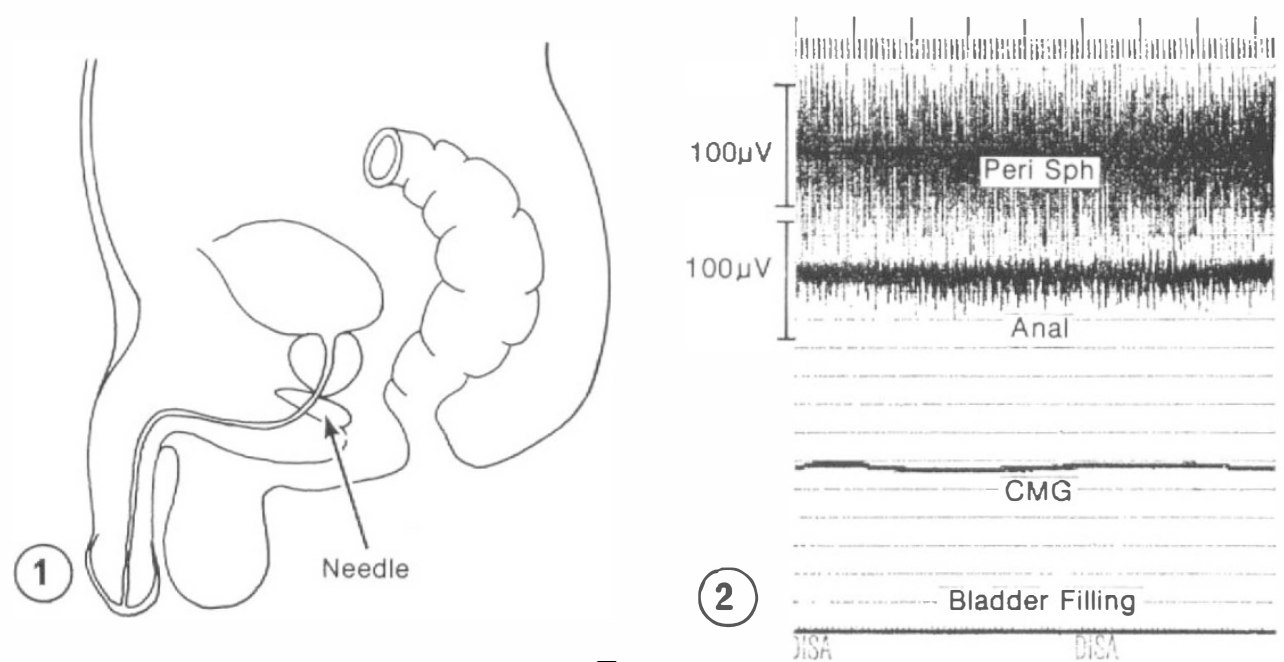

FIG. I

Indicates the direction of the coaxial needle placement into the periurethral striated sphincter which is guided with a finger in the rectum.

FIG. 2

Shows simultaneous CMG, anal and periurethral striated EMG during bladder filling. Motor unit activity picked up through anal electrode is of low amplitude compared to that of periurethral EMG.

left hand in the rectum. The perianal needle was placed at Io or 20 'clock position within about $\mathrm{I} \mathrm{cm}$ around the anal margin.

Studies were done on a 2 channel Disa EMG (I500) and were recorded on a 4 channel visicorder. A rectal balloon was also placed to find out true detrusor contractions.

\section{TABLE I}

Anal versus periurethral EMG activity $=50$ patients

\begin{tabular}{lll}
\hline (A) & Same activity & $=20$ Pts. $(40 \%)$ \\
(B) Diagnostic but anal activity of low & amplitude and reduced frequency & $=$ I3 Pts. $(26 \%)$ \\
(C) Spasticity from lower extremities & $=4$ Pts. $(8 \%)$ \\
spread to anal EMG & $=$ I Pt. $(2 \%)$ \\
(D) Spasticity spread to periurethral EMG & $=2$ Pts. $(4 \%)$ \\
(E) Anal better than periurethral & Periurethral activity present with & 10 Pts. $(20 \%)$ \\
(F) & absent anal activity &
\end{tabular}

\section{Results}

Comparison of results of perianal and periurethral electromyography simultaneously studied with CMG are shown in Table I. Twenty patients (40 per cent showed similar activity. Thirteen patients ( 26 per cent) showed diagnostic motor 
unit activity on both channels, but pick-up through the anal electrode was of low amplitude and reduced frequency (see Fig. 2). Five patients (Io per cent) with marked spasticity in the lower extremities demonstrated easy pick-up of large motor units (corresponding to involuntary lower extremity movement) by the needle in the anal sphincter but in only one patient was it picked up by the needle in the periurethral sphincter (see Figs $3 \mathrm{a}, \mathrm{b}$ ). The illustrated example shows (Fig. 3a) simultaneous CMG, anal and periurethral EMG in a patient with spasticity in whom large amplitude motor units were noted on anal EMG. However when another needle was placed in the left thigh (adductors) similar motor units were noticed (Fig. 3b). In two patients (4 per cent) activity was better recorded in anal than in the periurethral sphincter. Ten patients ( 20 per cent) showed absent anal activity with intact periurethral activity. Four out of these ten were tetraplegics, three paraplegics and three had cauda equina lesions. An illustrated example of such a patient with a cauda equina lesion is shown in Figure 4. There was absent anal EMG activity both during 'bladder empty' and 'bladderfilling phase'. Also, with the bladder contracted, simultaneous anal EMG activity remained absent but periurethral EMG activity persisted and there was some increase in the number of motor units firing synchronously with detrusor contractions. This patient was managed with limited transurethral sphincterotomy of the periurethral sphincter.
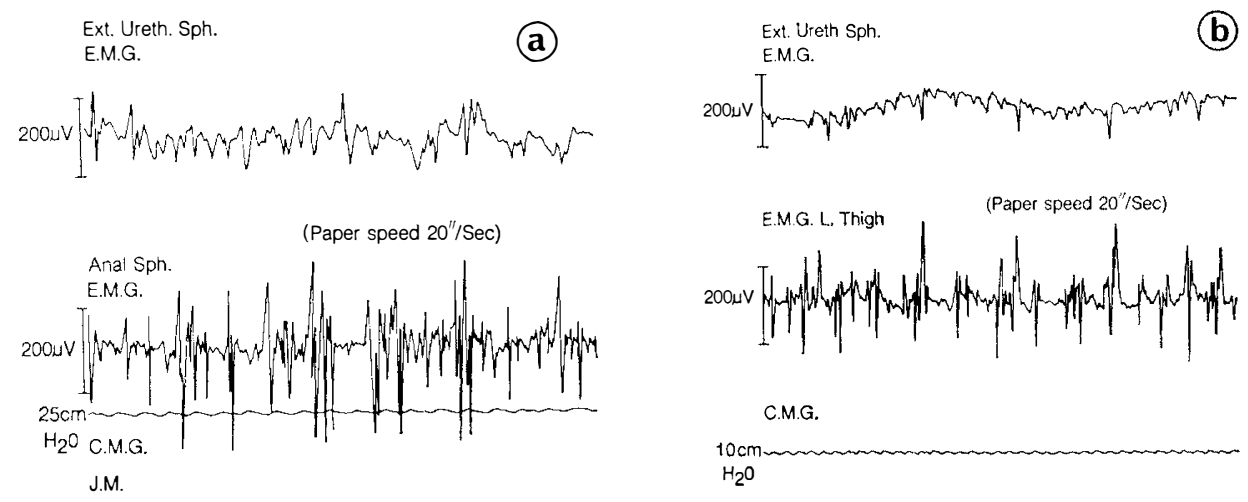

FIG. 3A

Shows simultaneous CMG, anal and peri-urethral striated EMG where large amplitude motor units were picked up by the anal electrode corresponding to the involuntary movements in the lower extremities.

FIG. 3B

With a needle in the left thigh (instead of anal EMG) shows similar motor units that were picked up in the anal electrode as in Figure $3 \mathrm{~A}$.

\section{Discussion}

The role of simultaneous cystomanometry and EMG of the perianal muscles as an investigative tool for the diagnosis of neuromuscular dysfunction of the bladder is well established (Scott et al., 1964; Sundin \& Petersen, 1975; Perkash, 1978). Cystometry combined with electromyography of the periurethral striated muscles is easy to perform and often gives more reliable information on the nature of an outflow obstruction than does the voiding cystogram. 


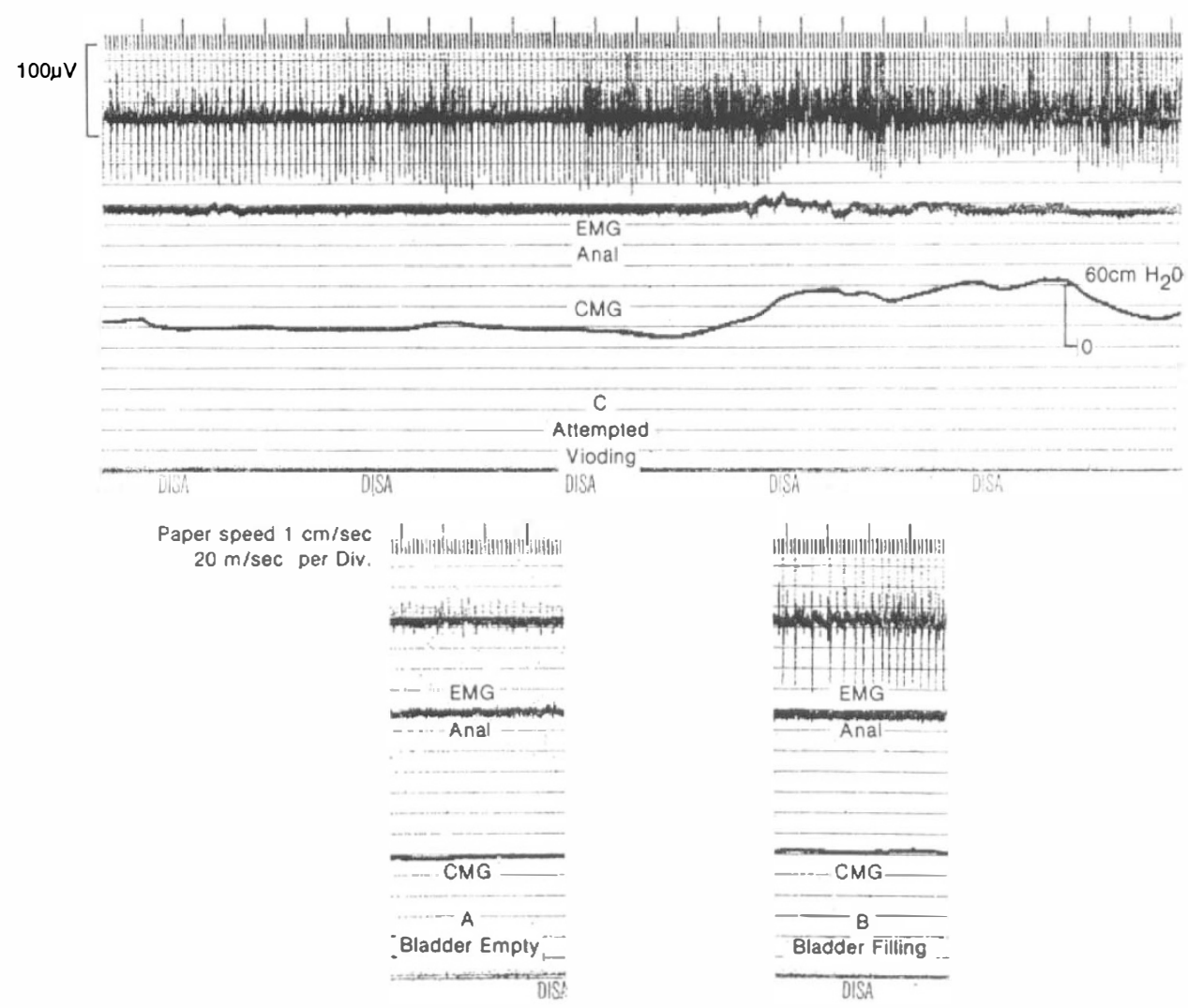

FIG. 4

Shows simultaneous CMG, anal and periurethral EMG with empty bladder (A), bladder filling (B), and during attempted voiding (C). With bladder empty (A), anal EMG activity was absent, but low grade activity was seen in the peri-urethral sphincter. With bladder filling (B) and at attempted voiding (C) anal EMG activity remained absent, but large number of motor units were recorded from the periurethral sphincter.

Analysis of the data from the present study indicates that periurethral EMG study along with CMG was diagnostic of urodynamic abnormality in 94 per cent patients whereas anal EMG study along with CMG was diagnostic only in 72 per cent patients with spinal injuries.

In ten patients ( 20 per cent) anal EMG activity was absent while periurethral activity was intact, while absence of anal EMG activity in patients with cauda equina injury is expected, seven of the ten had lesions above the cauda (three tetraplegics, four paraplegics). Absence of anal EMG activity in this latter group can only be explained on the basis of a double lesion with involvement of the lower as well as the upper cord.

Abramson et al. (1966) presented a clinically adaptable method of simultaneous recording of the intravesical pressure and indirect monitoring of the activity of the external urethral sphincter by means of electromyographic registration of the external anal sphincter activity. The observations on the urethro-anal reflex by Ruskin and Davis would suggest independent function of these two sphincters in the normal individual. Floyd and Walls using surface electrode 
showed that increased intra-abdominal pressure produced an increase in anal sphincter tone unless the patient was defecating. Also, dilatation of anal sphincter in normal man inhibits detrusor contraction and micturition (Koch \& Pompeius, 1963). The opposite effect may also be obtained whereby anal dilatation may facilitate micturition in spinal injury patients (Comarr, I96I). Review of the literature and the present study thus indicate that anal sphincter EMG may not provide adequate information for outflow obstruction whether studied in normals or even in spinal injury patients. Use of needles in the anal sphincter may pick up distant motor units from the periurethral sphincter but surface electrodes such as anal plugs (Brodley, I964) may not provide adequate information.

\section{Conclusion}

Urodynamic evaluation of 50 consecutive spinal injury patients with simultaneous cystometrography, anal and periurethral striated EMG is presented. For the precise urodynamic evaluation of the neuromuscular disorders of the bladder, it seems that (a) periurethral striated EMG along with CMG has better diagnostic value than the anal EMG along with CMG since adequate diagnosis was not possible in 28 per cent patients in the present series when only CMG-anal EMG had been carried out; and $(b)$ in spinal injury patients with cauda equina lesion, or a double lesion in the cord, or with associated marked spasticity, CMG-periurethral striated EMG seems more appropriate for the diagnosis of neuro-muscular abnormality. In such patients, periurethral striated muscle activity may still be intact and even responsible for detrusor-sphincter dyssynergia while anal sphincter musculature may be denervated due to an incomplete lesion.

\section{RÉSUMÉ}

L'auteur rapporte les conclusions tireés de l'examen urodynamique, associé à la cystométrographie et à l'EMG du sphincter anal et du sphincter strié de l'urètre, d'une série de 50 patients atteints de lésion spinale. Il apparaît que pour un bilan urodynamique précis des désordres neuromusculaires de la vessie:

(a) L'EMG du sphincter strié de l'urètre couplé à la cystométrie a une valeur diagnostique supérieure à celle de l'EMG du sphincter anal associé à la cystométrie. En effet, un diagnostic exact n'a pu étre fait, dans cette série, chez $28 \%$ des patients étudiés par l'association cystométrie-EMG du sphincter anal.

(b) En cas de lésion de la queue de cheval, de lésions médullaires étagées ou occasionnant une spasticité importante, la cystométrie coupleé à l'EMG du sphincter strié de l'urètre semble étre plus apte à faire le bilan des anomalies neuromusculaires. Chez de tels patients, du fait d'une lésion incomplète, l'activité du sphincter strié de l'urètre peut rester intacte et occasionner éventuellement une dyssynergie détrusor-sphincter si la musculature du sphincter anal est dénerveé.

\section{ZUSAMMENFASSUNG}

Urodynamometrische Messung von 50 aufeinanderfolgenden rückenmarkverletzten Patienten mit gleichzeitiger Blasendruckmessung, Harnröhrenumgebung quergestreifter Muskel-Elektromyographie ist dargestellt.

Für die genaue urodynamometrische Bestimmung der neuromuskulären Blasenstörungen scheint die Vereinigung der periurethralen quergestreiften Muskel-Elektromyographie mit der Blasendruckmessung diagnostisch wertvoller zu sein als die Kombination der Elektromyographie mit der Blasendruckmessung. Dies besteht, weil genaue Diagnose in $28 \%$ der Patienten nicht möglich war, solange nur der Blasendruck und die Afterelektromyographie aufgenommen wurden. Weiterhin, für die präzise Bestimmung der neurologischen Blasenstörungen in Patienten mit Cauda Equina Verletzung, oder mit einer 
Doppel-Läsion des Rückenmarks, Kombiniert mit ausserordentlicher Spastizität, scheint die Blasendruckverlauf Aufnahme mit quergestreifter Muskel-Elektromyographie für die Diagnose der neuromuskulären Abnormalitäten zweckmäßiger zu sein.

In solchen Patienten konnte die harnröhrenumgebende Muskel-aktivität unversehrt sein, und sogar auch für die Detrusor-Sphincter Dyssynergie verantwortlich sein, während die Muskulatur des Sphincter ani externus durch eine unvollständige Verletzung denerviert ist.

\section{REFERENCES}

Abramson, A. S., Roussan, M. S. \& D'Oronzio, G. (1966). Method for evaluating function of the neurogenic bladder. F.A.M.A., 195, 554 .

Bradley, W. E., Scott, F. B. \& TIMM, G. W. (1974). Sphincter Electromyography, Urologic clinics of North America I, No. I, 69-80.

ComarR, A. E. (I96I). Voiding by rectal stimulation among patients with spinal cord injury. F. Indian. Med. Prof., 8, 3630.

DenNY-Brown, D. \& Robertson, E. G. (1933). State of bladder and its sphincters in complete transverse lesions of spinal cord and cauda equina. Brain, 56, 397-463.

FLOYD, W. F. \& WALLS, E. W. (1953). Electromyography of sphincter ani externus in man. F. Physiol., 122, 599-609.

FranksSON, C. \& PETERSON, I. (1955). Electromyographic investigations of disturbances in the striated muscle of the urethral sphincter. Br. F. Urol., 27, I54.

KAWAKAMI, M. (1954). Electromyographic investigation on human external sphincter muscle of anus. Fap. F. Physiol., 4, 196.

Koch, N. G. \& PoMpeIUS, R. (I963). Inhibition of vesical motor activity induced by anal stimulation. Acta Chir Scand., 126, 244-250.

PeRKASH, I. (1978). Detrusor-sphincter dyssynergia and Dyssynergic responses: recognition and rationale for early modified transurethral sphincterotomy in complete spinal cord injury lesions. F. of Urol., 120, 469-474.

Ruskin, A. P. \& Davis, J. E. (I975). A new urethral reflex revealed by sphincter electromyography. Arch. Phys. Med. Rehabil., 56, 220.

SCOTT, F. B., QUESADA, E. M. \& CARDUS, D. (I964). Studies on the dynamics of micturition: observations on healthy men. F. of Urol., 92, No. 5, 455-463.

Sundin, T. \& Petersen, I. (1975). Cystometry and simultaneous electromyography from the striated urethral and anal sphincters and from levator ani. Invest. Urol., I3, No. I, 40-46.

TAVERNER, D. \& SMIDDY, F. G. (I969). Electromyographic study of normal function of external anal sphincter and pelvic diaphragm. Dis. Colon Rectum, 2: 153-160, MarchApril. 